\title{
Novel real-time PCR based assays for differentiating fall armyworm strains using four single nucleotide polymorphisms
}

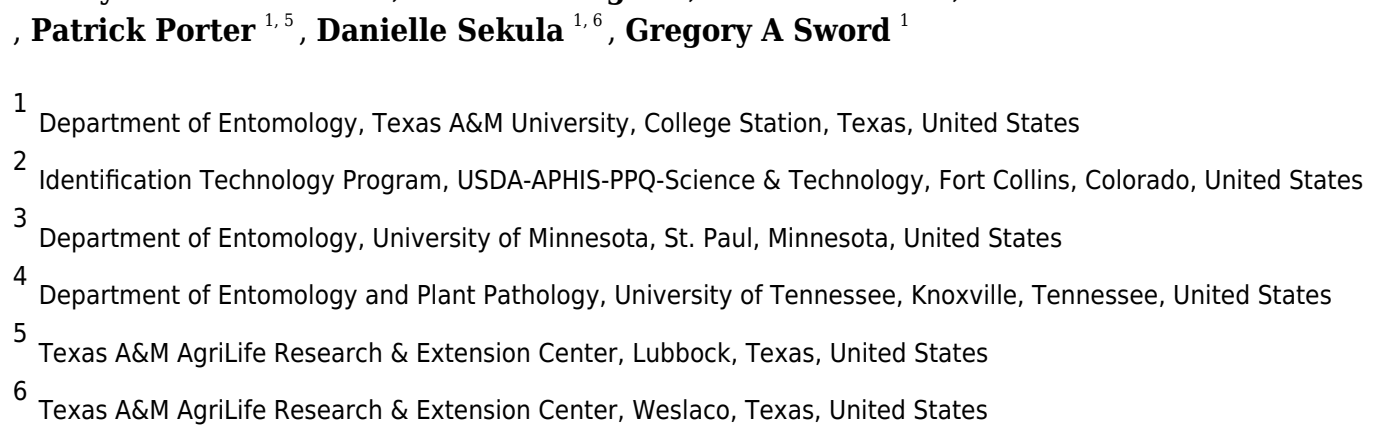

The fall armyworm, Spodoptera frugiperda, is a polyphagous global pest with a preference for gramineous crops such as corn, sorghum and pasture grasses. This species is comprised of two morphologically identical but genetically distinct host strains known as the corn and rice strains, which can complicate pest management approaches. Two molecular markers are commonly used to differentiate between strains, however, discordance between these markers can lead to inconclusive strain identification. Here, we used double digest restriction site associated DNA sequencing to identify diagnostic single nucleotide polymorphisms (SNPs) with alleles unique to each strain. We then used these strain-specific SNPs to develop four real-time PCR based TaqMan assays to rapidly and reliably differentiate between strains and interstrain hybrids. These assays provide a new tool for differentiating between strains in field-collected samples, facilitating future studies on strain population dynamics and interstrain hybridization rates. Understanding the basic ecology of $S$. frugiperda strains is necessary to inform future management strategies. 
2 Novel real-time PCR based assays for differentiating

3 fall armyworm strains using four single nucleotide 4 polymorphisms

Ashley E. Tessnow ${ }^{1}$, Todd M. Gilligan ${ }^{2}$, Eric Burkness ${ }^{3}$, Caroline Placidi de Bortoli ${ }^{4}$, Juan Luis Jurat-Fuentes $^{4}$, Patrick Porter ${ }^{1,5}$, Danielle Sekula ${ }^{1,6}$, Gregory A. Sword ${ }^{1}$

${ }^{1}$ Department of Entomology, Texas A\&M University, College Station, TX, USA

${ }^{2}$ USDA-APHIS-PPQ-Science \& Technology, Identification Technology Program, Fort

12 Collins, CO, USA

${ }^{3}$ Department of Entomology, University of Minnesota, St. Paul, MN, USA

${ }^{4}$ Department of Entomology and Plant Pathology, University of Tennessee, Knoxville, TN, USA

${ }^{5}$ Texas A\&M AgriLife Research \& Extension Center, Lubbock, TX, USA

${ }^{6}$ Texas A\&M AgriLife Research \& Extension Center, Weslaco, TX, USA

Corresponding Author:

Ashley E. Tessnow

22

2475 TAMU, College Station, TX, 77845, USA 


\section{Abstract}

39 The fall armyworm, Spodoptera frugiperda, is a polyphagous global pest with a preference for 40 gramineous crops such as corn, sorghum and pasture grasses. This species is comprised of two 41 morphologically identical but genetically distinct host strains known as the corn and rice strains, 42 which can complicate pest management approaches. Two molecular markers are commonly used 43 to differentiate between strains, however, discordance between these markers can lead to 44 inconclusive strain identification. Here, we used double digest restriction site associated DNA sequencing to identify diagnostic single nucleotide polymorphisms (SNPs) with alleles unique to each strain. We then used these strain-specific SNPs to develop four real-time PCR based

47 TaqMan assays to rapidly and reliably differentiate between strains and interstrain hybrids.

48 These assays provide a new tool for differentiating between strains in field-collected samples, 49 facilitating future studies on strain population dynamics and interstrain hybridization rates.

50 Understanding the basic ecology of S. frugiperda strains is necessary to inform future 51 management strategies.

\section{Introduction}

The fall armyworm, Spodoptera frugiperda (Lepidoptera: Noctuidae), is an important economic pest endemic to the Western Hemisphere. This species is highly polyphagous, feeding on more than 357 different host plants (Montezano et al., 2018), but it causes most economic damage to gramineous crops such as corn, sorghum, and pasture grasses (Johnson, 1987; Luginbill, 1928; Pashley, 1988). Although S. frugiperda is considered sporadic due to its 59 migratory behavior (Hardke et al., 2015), severe fall armyworm infestations can result in complete yield loss, making them a significant agricultural threat. As a result, integrative pest 
61 management (IPM) measures have been implemented to control this pest and keep populations

62 below an economic threshold (Prasanna et al., 2018; Sparks, 1986; Wiseman, 1985). The fall

63 armyworm recently invaded the Eastern Hemisphere and spread rapidly across most of Africa,

64 Southeastern Asia and into Australia, making this species a global concern (Goergen et al., 2016;

65 Otim et al., 2018; Sharanabasappa et al., 2019; Tay et al., 2020; Zhang et al., 2019).

66 One recently proposed method for suppressing fall armyworm populations in the field is

67 through the release of genetically modified (GM) fall armyworm adults carrying a self-limiting

68 female-lethal gene (Rwomushana et al., 2018; Stokstad, 2020). Because wild moths that mate

69 with the introduced GM moths would only produce male offspring that perpetuate the female

70 lethal gene, the number of females in the population is dramatically reduced over several

71 generations. This technique has been effective at reducing the populations of multiple insect

72 pests, including the yellow fever mosquito (Aedes aegypti), the Mediterranean fruit fly (Ceratitis

73 capitata), and the diamondback moth (Plutella xylostella) (Asadi et al., 2020; Carvalho et al.,

74 2015; Harvey-Samuel et al., 2015).

75 One factor that complicates fall armyworm IPM, especially the potential for releasing

76 GM insects, is the existence of two morphologically identical yet genetically distinct sympatric

77 strains. These strains were originally described as host associated by Pashley (1986), with the

78 corn-strain (C-strain) primarily associated with large-blade grasses such as corn and sorghum,

79 and the rice-strain (R-strain) primarily associated with small-blade pasture grasses (Pashley,

80 1988, 1986). Despite these associations, the host range of these strains largely overlaps, and both

81 strains are frequently collected in the same traps, especially in corn and sorghum fields (Groot et

82 al., 2010; Machado et al., 2008; Meagher and Nagoshi, 2004; Nagoshi and Meagher, 2004;

83 Prowell et al., 2004). Assortative mating (Schöfl et al., 2011) and hybrid sterility (Kost et al., 
84 2016) have contributed to maintain genetic divergence between $S$. frugiperda strains (Gouin et

85 al., 2017) also suggesting interstrain hybridization is likely limited and releasing GM moths may

86 only control one of the two strain types. In order for GM fall armyworms or any other strain-

87 specific management approach to be effective, a much better understanding of their population

88 dynamics and frequency of interstrain hybridization is needed.

89 No consistent morphological differences have been found to differentiate between C-

90 strain and R-strain fall armyworms to date (Nagoshi et al., 2020). As a result, molecular markers

91 are required to distinguish between the two strains. Two molecular markers are commonly used

92 to identify the strains. The first relies on polymorphisms in the mitochondrial cytochrome

93 oxidase I (COI) gene, as described by Nagoshi et al. (2006). These polymorphisms create unique

94 restriction enzyme cutting sites that can be analyzed using RFLP analysis. The second marker

95 used targets a series of single nucleotide polymorphisms (SNPs) in the Z-linked Triosephosphate

96 isomerase (Tpi) gene (Nagoshi, 2010). Unfortunately, disagreement in strain identification

97 between these two markers is often observed (Schlum et al., 2021) and has been reported in up to

$9824 \%$ of field-collected moths (Nagoshi, 2012), leading to some uncertainty in correct strain

99 assignment. This discordance could be the result of occasional hybridization, a phenomenon that

100 has been observed in the lab (Dumas et al., 2015; Kost et al., 2016; Pashley and Martin, 1987;

101 Whitford et al., 1988) and in field samples (Schlum et al., 2021) However, the fact that these

102 genetic markers have not become homogenous over time suggests the two strains remain

103 genetically distinct despite occasional gene flow (Schlum et al., 2021).

104 Recent advances in sequencing and real-time PCR allow for the development of novel

105 molecular diagnostic assays based on single nucleotide polymorphisms (SNPs). Fluorogenic

106 real-time PCR-based TaqMan ${ }^{\circledR}$ assays, originally developed by Livak et al., (1995) are a rapid 
107 and effective method for differentiating between specific alleles at a known SNP locus. This

108 technology has been successfully used previously in S. frugiperda to detect insecticide resistance

109 alleles (Banerjee et al., 2017). In this study, we used ddRAD-Seq data to identify novel SNP

110 markers with unique alleles characterizing the two fall armyworm strains. We then developed

111 four new real-time PCR-based TaqMan assays to rapidly and reliably differentiate between

112 strains. These assays were validated using fall armyworm samples of each strain and their

113 interstrain hybrids that were collected across both the central and eastern US flyways

114 (Westbrook et al. 2016). Strain assignment results were compared to those of the two commonly

115 used markers for strain differentiation, $C O I$ and $T p i$. The assays developed here provide a new

116 tool for identifying fall armyworm strains that enhance our confidence in strain determination

117 and will facilitate future studies on population dynamics and interstrain hybridization in this

118 important pest.

\section{Materials \& Methods}

121

122

123

124

125

126

127

128

129

\section{TaqMan Assay Development}

Sample collection

Spodoptera frugiperda moths were collected using universal moth traps baited with

Scentry PSU 2-component lures (Scentry Biologicals, Billings, MT) and containing Hercon Vaportape. Each trap was placed around corn and sorghum fields at five locations across the central US, and samples were collected at multiple time points throughout the year (Table 1).

During each sampling time, traps were checked daily until a minimum of 24 moths were captured. At sites in the Lower Rio Grande Valley, larvae were occasionally hand collected from nearby host plants. All sampled insects were immediately preserved in $95 \%$ ethanol and stored at 
$1304^{\circ} \mathrm{C}$ until shipment to Texas A\&M University in College Station, TX. Upon arrival, all

131 specimens were stored at $-80^{\circ} \mathrm{C}$ until DNA extraction. In total, DNA from 426 moths was 132 sequenced across two years.

133

134

136

137

138

139

140

141

142

143

144

145

146

147

148

149

150

151

152

\section{DNA Extraction}

Prior to DNA extraction, the thorax was isolated from each specimen and surface sterilized in $95 \%$ ethanol. Tissues were tapped dry, placed individually in $2 \mathrm{ml}$ Eppendorf tubes, and then frozen in liquid nitrogen. Sterilized plastic pestles were used to macerate the frozen thorax tissue. DNA was extracted using the Qiagen Gentra Puregene Tissue Kit, following the manufacturer's protocol. The concentration of each DNA sample was measured on a Fluorometer (DeNovix) and all samples were diluted to a concentration of $50 \mathrm{ng} / \mu \mathrm{l}$. During assay development all individuals assessed were males. However, if these assays are to be applied to female moths, it is important to avoid abdominal tissue as DNA within a mated female's spermatheca could interfere with strain assignment.

\section{Strain Haplotype Determination}

Prior to sequencing, strain identifications were assigned to each DNA sample based on two known RFLPs in the Cytochrome C Oxidase Subunit I (COI) mitochondrial gene, to ensure that individuals of both the C- and R- strain were represented in our collection (Levy, GarciaMaruniak, \& Maruniak, 2002; Nagoshi et al., 2006). Briefly, the primer pair JM-76/JM-77 was used to amplify a $568 \mathrm{bp}$ fragment of COI (Levy et al., 2002). And aliquot of the amplicon (4 $\mu 1)$ was then digested with 50 units of SacI (New England BioLabs) and 50 units of MspI (New England BioLabs). Reactions were incubated at $37^{\circ} \mathrm{C}$ for 1 hour, and the products were run on a 
$1531.8 \%$ agarose gel. The amplified C-strain mtDNA is cut once by MspI and not by SacI, while the

154 R-strain mtDNA shows the reciprocal pattern (Nagoshi et al., 2006). Based on the cutting

155 patterns of both restriction enzymes, each individual was assigned as having either a C-strain or

156 an R-strain mitochondrial haplotype. After haplotype determination, DNA was stored at $-20^{\circ} \mathrm{C}$

157 until sequencing.

158

159

DNA Sequencing, SNP Calling and Filtering

160

Purified DNA samples were sent to Texas A\&M AgriLife Genomics and Bioinformatics

161

Services (TxGen) for quality control, library preparation, and double digest restriction-site

162

associated DNA sequencing (ddRADseq) (Peterson et al., 2012). Prior to library prep, DNA was

purified using the Agencourt AMPure XP purification system. Libraries were prepared by

digesting the total genomic DNA with MseI and EcoRI restriction enzymes, and 300-500 bp

fragments were size selected for sequencing. Each fragment was ligated to standard Illumina

adapters, sequencing primers, and multiplexing indexes. All sequencing was conducted on the

Illumina NovaSeq 6000 to yield 150 bp paired end reads. Sequence cluster identification, quality

prefiltering, base calling and uncertainty assessment was then conducted using Illumina's NCS

1.0.2 and RFV1.0.2 software with default parameter settings.

After demultiplexing and quality analysis by FastQC, sequences were uploaded into the

171 Texas A\&M High Performance Research Computing 'Ada' cluster for bioinformatic analyses.

172 All sequences are now available through the NCBI Sequence Read Archive bioproject under

173 accession number PRJNA645462

174 (https://www.ncbi.nlm.nih.gov/bioproject/?term=PRJNA645462). 
176 strain

177 (https://bipaa.genouest.org/sp/spodoptera_frugiperda_pub/download/genome/corn/v3.1/sfru.mais

178 .corrected.3.1.fa) and R-strain

179 (https://bipaa.genouest.org/sp/spodoptera frugiperda pub/download/genome/rice/v1.0/Spodopte

180 ra frugiperda_rice 1.0.fa) published S. frugiperda genomes (Gouin et al., 2017). Sequences that 181 did not match uniquely to one or both genomes were removed to clear the remaining sequences 182 of all potential microbial or host contaminant DNA. Forward and reverse reads were then 183 matched using the repair function in BBMAP v.3.8.08 (Chaisson and Tesler, 2012).

184 Genomic loci containing SNPs were identified using the dDocent v.2.2.16 pipeline 185 (Puritz et al., 2014). In brief, dDocent removed low quality bases using Trimmomatic, and then 186 mapped reads to the published chromosome map for S. frugiperda (Liu et al., 2019, 187 http://ftp.cngb.org/pub/CNSA/data2/CNP0000513/CNS0099235/CNA0003276) using BWA. 188 The program FreeBayes then identified genomic loci containing SNPs and indels, and these 189 variants were concatenated into a single VCF file. Our initial VCF file contained 441,437 190 variants.

191 Variants were filtered using VCFtools v.0.1.16 (Danecek et al., 2011). Specifically, all 192 indels were removed and the remaining SNPs were filtered for a minimum PHRED score of 30. 193 Only SNPs that were present in all individuals at a minimum of 3x coverage were kept in the 194 final dataset. Finally, the dDocent_filters script 195 (https://github.com/jpuritz/dDocent/blob/master/scripts/dDocent_filters) was run to complete 196 SNP filtering. After filtering, the VCF file was manually examined and 236 SNPs did not map to 
197 a specific chromosome but rather to an 'unplaced_scaffold.' These unmapped SNPs were

198 removed, leaving 5,439 mapped SNPs in the final dataset.

199

200 TaqMan Assay Development

201 To identify strain specific SNP loci, fixation indices $\left(\mathrm{F}_{\mathrm{st}}\right)$ between individuals identified

202 as having C- strain or R- strain mtDNA were calculated for each of the 5,439 mapped SNPs

203 using R v.3.6.2/genepop (Rousset, 2008). All SNPs with $\mathrm{F}_{\text {st }}$ values greater than 0.7 were

204 identified for further analysis. Each of these SNPs were mapped to the Liu et al. (2019)

205 chromosome map in Geneious v.11.0.2, and 250 bp upstream and downstream of each SNP was

206 extracted (501 bp region total). If any of the other 5,439 identified SNPs were present in this 501

207 bp region, the reference nucleotide was denoted as ' $N$ '. In several cases, divergent SNPs were in

208 close proximity to one another in the genome.

209 All extracted sequences containing divergent SNPs were manually examined in Geneious

210 to assess the variability in each region and the possibility of designing high quality primer and

211 hydrolysis probe sequences. Of the 41 initial SNPs with $\mathrm{F}_{\text {st }}$ values $>0.7$, four were selected to test

212 for TaqMan real-time PCR assay development, referred to here as SNP A, B, C, and D. These

213 SNPs were selected due to their spacing in the genome and their proximity to other known

214 polymorphisms that could have interfered with primer and probe binding.

215 The $501 \mathrm{bp}$ sequence containing each divergent SNP was uploaded to the Custom

216 TaqMan Assay Design Tool offered through ThermoFisher Scientific

217 (https://www.thermofisher.com/order/custom-genomic-products/tools/genotyping/). This

218 program identifies the optimal primer and probe sequences for real-time PCR based SNP

219 genotyping. In order to increase the melting temperature $(\mathrm{Tm})$ of each hydrolysis probe while 
220 maintaining the short length, each probe was designed with a minor groove binder (MGB)

221 moiety at the 3' end. Each probe contained either a FAM or VIC fluorescent reporter dye on the

2225 ' end and a non-fluorescent quencher (NFQ) on the 3' end. Probes designed to bind to the R-

223 strain and C-strain SNPs were bound to a FAM or VIC fluorophore, respectively. Primer and

224 probe sequences are provided in Table 2. The context sequence and ThermoFisher assay IDs that

225 can be used to purchase these custom assays are listed in Table S1. The development of these

226 real-time PCR assays followed MIQE guidelines (Bustin et al., 2009).

227

228 TaqMan Assay Validation

229 Sample collection

230 We conducted three rounds of assay validation using 1) previously sequenced samples of 231 known genotypes, 2) samples of unknown strain from the central US flyway, and 3) samples of

232 unknown strain collected from the eastern US flyway. In the initial validation, 20 individuals that

233 had previously been sequenced as part of the assay development were selected. These included 8

234 samples with the C-strain genotype, 8 with the R-strain genotype, and 4 samples that were

235 identified as interstrain hybrids. In the second round of validation, DNA was extracted from 48

236 moths that were collected across the central flyway between 2017 and 2020. These moths had

237 not previously been sequenced and the strain genotype was unknown. For the final validation, a

238 collection of DNA from 44 moths collected between 2012 and 2017 at several locations in the

239 eastern US was used. The collection information of all moths that were used in assay validation

240 can be found in Table 3.

241

242 Strain determination using COI and Tpi

Peer] reviewing PDF | (2021:05:60854:1:0:NEW 18 Aug 2021) 
244 the strain of all samples at previously described COI and Tpi markers using RFLP analysis. The

245 same method described above to determine strain haplotype for each sequenced individual was

246 used to assess the COI strain marker for each individual used in the assay validation. Briefly, a

$247568 \mathrm{bp}$ fragment of the COI gene was amplified and then digested with the restriction enzymes

$248 \mathrm{MspI}$ and SacI. The product was run on a 1.8\% agarose gel to assess the restriction enzyme cut

249 sites. Because COI is maternally inherited, hybrids could not be detected using this method (Fig. 250 1).

251 To identify strain using the Tpi marker, an approximately $600 \mathrm{bp}$ fragment of the fall 252 armyworm Tpi gene was amplified using the primer pair Tpi-632 F/Tpi-1195R described by 253 Nagoshi (2012). In this reaction, initial denaturation occurred for 1 min at $94^{\circ} \mathrm{C}$, followed by 32 254 cycles of the following protocol: $92^{\circ} \mathrm{C}$ for $30 \mathrm{sec}, 57^{\circ} \mathrm{C}$ for $30 \mathrm{sec}, 72^{\circ} \mathrm{C}$ for $1 \mathrm{~min}$. The reaction 255 was then held at $72^{\circ} \mathrm{C}$ for three minutes. An aliquot $(2 \mu 1)$ of the PCR product was then digested 256 with 50 units of MspI (New England BioLabs) following the manufacturer's protocol. This 257 reaction was held at $37^{\circ} \mathrm{C}$ for $1 \mathrm{hr}$ and then the resulting product was run on a $1.8 \%$ agarose gel. 258 The resulting banding patterns for C-strain, R-strain and hybrid individuals after RFLP analysis 259 of both COI and the Tpi gene are shown in Figure 1.

Strain determination using TaqMan real-time PCR assays

262 Real-time PCR assays were conducted as $10 \mu 1$ (final volume in TE buffer) reactions in 263384 well plates. Each reaction contained $1 \mu 1$ of template DNA diluted to $20 \mathrm{ng} / \mu 1,5 \mu 1$ of 264 TaqMan Genotyping Master Mix (Applied Biosystems), $0.5 \mu 1$ of 40x Custom ThermoFisher 265 TaqMan assay containing the primers and hydrolysis probes (assay information listed in Table 
266 2), $0.05 \mu 1$ of Precision Blue Real-Time PCR Dye (BioRad). Non-template controls included 1

$267 \mu 1$ of TE buffer instead of DNA, and all reactions were conducted in duplicate. The real-time

268 PCR program began by holding samples at $95^{\circ} \mathrm{C}$ for $10 \mathrm{~min}$, followed by 40 cycles oscillating

269 between $95^{\circ} \mathrm{C}$ for $15 \mathrm{sec}$ to $60^{\circ} \mathrm{C}$ for $1 \mathrm{~min}$. After being held at $60^{\circ} \mathrm{C}$ for $1 \mathrm{~min}$, fluorescence was

270 recorded across all four channels of a CFX384 Touch Real-Time PCR Detection System

271 (BioRad). All samples were assessed individually at each of the 4 diagnostic SNP loci (SNP A,

272 B, C, and D).

273

All real-time PCR data were input into the CFX Maestro software (BioRad) to determine

274 the quantification cycle (Cq) values (number of cycles for fluorescence detection above

275 background threshold) for both FAM and VIC in each reaction. The CFX Maestro software

276 identified each sample as either homozygous for the R-strain allele (primarily FAM fluorophore

277 detected), homozygous for the C-strain allele (primarily VIC fluorophore detected), or

278 heterozygous at the locus of interest (both fluorophores detected at similar levels). If both the

279 FAM and VIC fluorophores were detected in a reaction, the difference between the Cq values of

280 each fluorophore was calculated for each individual ( $\Delta \mathrm{Cq})$. The $\Delta \mathrm{Cq}$ across all homozygous

281 individuals was then averaged for each allele and is presented as the $\Delta \mathrm{Cq}$ within each strain.

282 A consensus strain determination was made for all unknown individuals. This consensus

283 was reached if a minimum of 5 out of the 6 diagnostic assays ( 4 real time PCR +2 RFLP

284 analyses) agreed on the strain call. The number of individuals that matched the consensus

285 sequence was calculated for each assay. A chi-square test in JMP 14.0. (SAS Institute Inc,. Cary,

$286 \mathrm{NC}, \mathrm{USA}$ ) was used to determine if there was a statistically significant difference in accuracy

287 between the six diagnostic assays. In this case, accuracy was defined as the proportion of

288 individuals matching the consensus strain assignment. 
290

291

292

293

294 295 296 297 298 299 300 301 302 303 304 305 306 307 308 309 310

Real-time PCR assay sensitivity analysis

The sensitivity of all real-time PCR assays was assessed using serial dilutions of DNA extracted from 3 R-strain and 3 C-strain fall armyworm moths. The samples selected for sensitivity analysis were all previously sequenced, and thus the allele present at each of the SNP sites was known. The DNA concentration was measured using a Fluorometer (DeNovix) and each sample was then diluted to $100 \mathrm{ng} / \mu \mathrm{l}$. Six serial dilutions were prepared by adding $1 \mu \mathrm{lof}$ DNA to $9 \mu 1$ of nuclease free water resulting in DNA concentrations of: $100,10,1,0.1,0.01$, 0.001, $0.0001 \mathrm{ng} / \mu 1$. The resulting Cq values of two duplicate runs were averaged for each SNP.

No assay was able to detect fluorescence at $0.0001 \mathrm{ng} / \mu 1$, so this concentration was removed from further analysis. The average $\mathrm{Cq}$ values across biological replicates were plotted against the $\log$ transformed DNA concentration. A linear regression was then fit in JMP ${ }^{\circledR}$ Pro 14.0.1 (SAS Institute Inc., Cary, NC) to determine the slope, $y$-intercept, and correlation $\left(\mathrm{R}^{2}\right)$ between DNA concentration and assay sensitivity

\section{Results}

\section{Diagnostic SNP Identification}

Of the 426 moths collected, 241 were identified as the C-strain and 185 were identified as the R-strain using known polymorphisms in the COI mitochondrial gene. After filtering the sequence data of these moths, 5,439 high quality biallelic SNPs were identified, 41 of which had Fst values higher than 0.7 between the two strains. This indicated that these SNP markers may exhibit a significant level of strain identity. Virtually all diagnostic SNPs identified were located on the Z-chromosome. Of the 41 initial SNPs with $\mathrm{F}_{\text {st }}$ values $>0.7$, four were selected to test for 
312 TaqMan real-time PCR assay development, referred to here as SNP A, B, C, and D. These SNPs

313 were selected due to their spacing in the genome, their proximity to other known polymorphisms,

314 and their Fst values. SNP A, B, and C are located on the Z-chromosome and had Fst values of

315 ranging from 0.77 to 0.79 and SNP D was located on chromosome 16 that had an Fst value of

316 0.74. BLAST results suggest that these four SNPs do not result in changes to the amino acid

317 sequence of any protein.

318

319 TaqMan assay validation for four SNPS

320 In the first round of validation using samples of known genotypes, all four SNP-based

321 TaqMan assays were able to accurately differentiate between C-strain (VIC fluorophore) and R-

322 strain individuals (FAM fluorophore). Additionally, the SNP A and SNP D assays accurately

323 identified all five-hybrid individuals as heterozygous at the SNP markers. Two of the hybrid

324 individuals were identified as homozygous for the C-strain allele at SNP marker B and C. Upon

325 further examination of our original sequencing data, we found that these individuals were indeed

326 homozygous for the C-strain allele at these loci, indicating our assays correctly identified the

327 individual genotype at the locus of interest, but hybrid individuals may not always be

328 heterozygous at these loci.

329 In our final two validations using individuals of unknown genotypes from both the

330 eastern and central US flyways, our assays detected a relatively even mix of C- and R-strain,

331 with 42 individuals being consistently identified as the R-strain, and 50 individuals being

332 consistently identified as the C-strain in at least 3 out of our 4 SNP assays.

333 The average Cq value for both fluorophores across all four SNP assays ranged from

33422.91 to 23.93 in homozygous individuals. In most reactions, some level of fluorescence was 
335 detected for both FAM and VIC fluorophores by the end of cycle 40. In order to determine the 336 number of cycles the target allele was detected before the off-target allele, we calculated the

337 difference in the Cq value for each fluorophore within each strain. For all homozygous R-strain

338 individuals, the FAM fluorophore was detected after a lower number of cycles, therefore the

$339 \Delta \mathrm{Cq}$ within the $\mathrm{R}$-strain was calculated as $\mathrm{Cq}_{\mathrm{VIC}}-\mathrm{Cq}_{\mathrm{FAM}}$. For all homozygous $\mathrm{C}$-strain

340 individuals, the VIC fluorophore was detected after a lower number of cycles, therefore the $\Delta \mathrm{Cq}$

341 with the $\mathrm{C}$-strain was calculated as $\mathrm{Cq}_{\mathrm{FAM}}-\mathrm{Cq}_{\mathrm{VIC}}$ (Table 4). The $\Delta \mathrm{Cq}$ for all heterozygote

342 individuals across all SNP based TaqMan assays ranged from 0-2, indicating almost equal signal

343 of both fluorophores. For SNP A, the VIC reporter dye was never detected above threshold for

344 R-strain individuals, and for SNP C the FAM reporter dye was never detected above the

345 threshold in C-strain individuals (Table S2 \& S4). For SNP B, some fluorescence was detected

346 by both FAM and VIC regardless of the individual's allele, however the fluorescence of the off-

347 target probe was always detected more than 15 cycles after the fluorescence of the target probe,

348 which is sufficient to accurately identify the strain (Table S3). For SNP D, FAM and VIC

349 fluorescence was detected in all individuals regardless of the allele present, and the fluorescence

350 of the off-target probe was often detected only 3 cycles after fluorescence of the target probe

351 (Table S5). This off-target probe binding could result in an overlap of fluorescence between the

352 two reporter dyes, especially in assays with high DNA concentration. As a result, this marker

353 may be less effective than the other three at differentiating between C-and R-strain individuals.

354 Because of these limitations, when the sex of the individuals being genotyped is known to be

355 male as is the case with most pheromone baited moth traps, we recommend using SNP A, B, and

$356 \mathrm{C}$ for strain determination. Based on the results of the assay validations, instructions for

357 implementing each of the four SNP based TaqMan assays are detailed in supplementary figures 
358 S1-S4. Additionally, Excel spreadsheet formulas (Microsoft ${ }^{\circledR}$ Excel Version 16.52) that can be

359 used to determine strain from real-time PCR results are included in Table S6.

360 Comparison between TaqMan assays, COI, and Tpi markers

361 In addition to the four SNP based real-time PCR diagnostic assays, we also determined

362 the strain of fall armyworm samples collected in both the central and eastern US flyways

363 (Westbrook et al. 2016), using two previously described diagnostic RFLP analyses (COI and

$364 T p i)$. In $97.3 \%$ of individuals assessed, at least 5 of the 6 combined SNP and RFLP diagnostic

365 assays were in agreement with the strain call (Table S6). In these cases, the consensus strain was

366 determined for each individual. Three individuals did not show a consensus between assays. Two

367 of these were previously sequenced individuals that were known to be hybrids, and one was a

368 non-sequenced individual from Collier (FL) that we suspect may also have been of hybrid

369 descent. Given the unknown genotype of the individual from Collier, this sample was removed

370 from assessments of assay accuracy.

371 For each assay, we determined the number of individuals that disagreed with the

372 consensus strain call. The Tpi marker had the lowest accuracy with 7 individuals showing

373 disagreement from the consensus strain, and SNP A had the highest consistency with 2

374 individuals showing disagreement with the consensus strain. We used a Pearson's Chi square test

375 to determine if the proportion of accurate calls significantly differed amongst our six assays, and

376 no differences were detected (Fig. $2, X^{2}=17.14$, $p=0.07$ ).

377

378 Sensitivity analysis results

379 Serial dilutions of genomic DNA from known R- and C-strain individuals were used to

380 assess the sensitivity of all four TaqMan real-time PCR assays to initial DNA concentration. 
381 Across all assays, no fluorescence was detected when $<0.001 \mathrm{ng}$ of DNA was added to the

382 reaction. When more than $0.001 \mathrm{ng}$ of DNA was added, there was a linear increase in the Cq of

383 each reaction as DNA concentration decreased, with $\mathrm{R}^{2}$ values ranging from $0.982-0.999$ across

384 all assays and fluorophores (Fig. 3). These results indicate that all four of our TaqMan real-time

385 PCR assays are capable of detecting the allele present at each loci when using 0.001-100 ng of 386 gDNA.

387

\section{Discussion}

We present four new diagnostic SNP markers to differentiate between the $\mathrm{C}$ and $\mathrm{R}$ fall

390 armyworm strains. Prior to this study, the two most commonly used molecular markers to discriminate these strains relied on polymorphisms in the mitochondrial gene COI or the Zlinked gene Tpi (Nagoshi, 2010; Nagoshi et al., 2006). However, discordance between these markers has been known to cause confusion in strain assignment. All four of the new SNP- based diagnostic assays were able to assign strain with equal accuracy when compared to the original COI and Tpi assays. Therefore, the addition of four new diagnostic markers will allow for increased confidence in the strain assignment. Furthermore, $C O I$ is maternally inherited and thus cannot identify hybrid heterozygotes, and Tpi is Z-linked and thus can only detect hybrids in males who have two copies of the $\mathrm{Z}$ chromosomes (ZZ). Three of our four diagnostic SNPs 399 (SNPs A-C) were also located on the Z-chromosome and thus have the same limitations as Tpi,

400 however, SNP D is located on chromosome 16, and thus could be used to identify hybrid 401 heterozygotes of both males and females. This new diagnostic marker in the nuclear genome 402 (chromosomes 2-31) could facilitate studies on interstrain hybridization in the field. 
All four of the TaqMan assays presented here could effectively assign a fall armyworm

404 strain when provided as little as $0.001 \mathrm{ng}$ of DNA. This could be very useful for strain assignments when only a small amount of DNA is recovered. However, when $1 \mathrm{ng}$ or less of DNA was present in the reaction, the Cq value increased above 30 cycles, potentially reducing the reliability of these assays. Therefore, if resources allow, we suggest that at least $10 \mathrm{ng}$ of DNA be included in normal assay runs. The $\Delta \mathrm{Cq}$ value of the SNP D marker was between 3-6 cycles indicating that both the target and non-target probes were binding to the DNA sequence containing the SNP. Although the target probe bound preferentially and was evident at least 3 cycles before the off-target probe, very high DNA concentrations may result in homozygous individuals being identified as hybrid heterozygotes due to a lack of probe specificity. When

413 only 20 ng of DNA were added to the reaction this marker was as accurate at assigning strain as 414 the rest. The probes for all other SNP markers were more specific, resulting in lower off-target 415 probe fluorescence regardless of DNA concentration. Across all individuals screened, at least five of the six diagnostic markers were in agreement (4 SNP assays $+C O I+T p i)$. Therefore, to streamline the diagnostic process and 418 reduce the number of reagents needed, only three diagnostic assays are required to confidently identify strain. Since all TaqMan assays require essentially the same reagents and have the same reaction conditions, they can be assessed simultaneously on the same real-time PCR plate. Thus, 421 it would be most efficient to assess the strain of unknown fall armyworm samples using three of 422 our SNP based diagnostic markers. Because of their higher reliability, we recommend that SNPs 423 A-C be used when determining the strain of moths that are known to be males, as is often the 424 case for most moth pheromone trap captures. Since male moths have two copies of the Z425 chromosome, hybrid determination would still be possible and reliable under these conditions. 
426 However, if researchers are interested in determining the strain of females or individuals of

427 unknown sex as is often the case with caterpillar collections, they may elect to use assays A, C,

428 and D. Because females only have a single copy of the $\mathrm{Z}$ chromosome, the autosomal marker on

429 chromosome 16 could then be used to more reliably identify hybrids. In the future, TaqMan

430 assays could also be developed for the strain specific markers located in the COI and Tpi genes

431 and run in concert with the SNP based markers described here. This would streamline the

432 genotyping process across all six known diagnostic markers.

433 In the United States there are only two locations where fall armyworms are currently

434 known to overwinter, south Texas and south Florida (Luginbill, 1928; Nagoshi and Meagher,

435 2008; Sparks, 1979; Westbrook et al., 2016), creating two populations in the US referred to as

436 the central and eastern populations. These populations are commonly thought to be genetically

437 distinct based on consistent differences in the ratios of mitochondrial haplotype that occur in

438 each population (Nagoshi et al., 2017, 2012, 2008). However, recent genomic studies using SNP

439 data suggest that little genomic differentiation exists between the two geographic overwintering

440 populations (Schlum et al., 2020). In this study, the identification of diagnostic SNPs was

441 conducted using only data from the central population, but all four diagnostic markers were still

442 capable of identifying the strain of insects across both the central and eastern populations. The

443 efficacy of our diagnostic markers across both overwintering populations further supports the

444 idea that some level of population panmixia occurs, despite geographic differences in the eastern 445 and western overwintering locations.

$446 \quad$ Although the assays described here were validated using fall armyworm moths collected

447 in the United States only, we expect that these assays would reliably differentiate between strains

448 across the Western Hemisphere because several studies have shown that very little genetic 
449 differentiation exists between the central US and South and Central America (Schlum et al. 2020, 450 Clark et al. 2007, Belay et al. 2012). It is therefore likely that some level of population panmixia 451 occurs throughout the hemisphere, resulting in similar genetic makeups across the large 452 geographic range. More recently, fall armyworms were introduced and subsequently spread 453 across Africa, Asia and Australia. Evidence suggests that the fall armyworm populations present 454 in the Eastern Hemisphere descended from a population with a large proportion of $\mathrm{C} x \mathrm{R}$ hybrids 455 (Nagoshi 2019). Although it is now thought that the majority of fall armyworms in the Eastern 456 Hemisphere are most similar to the C-strain (Nagoshi et al. 2019), alleles typically associated 457 with the R-strain may still be present in this invasive population due to their hybrid ancestry. As 458 a result, it remains to be tested whether the SNP assays developed here are capable of 459 differentiating strains in the newly invaded range. As a novel management strategy, efforts are being made to reduce the fall armyworm

461 462 463 464 465 466 467 468 469 470 numbers by introducing GM moths that contain a self-limiting female lethal gene. The success of this approach would be affected by dynamics of interstrain variation in fall armyworm population. Because the same mitochondrial haplotypes have been used to differentiate between strains over several decades, reproductive isolating barriers likely exist between strains as a result of either host use (Pashley, 1986), pheromone composition (Groot et al., 2008; Lima and McNeil, 2009), or nightly mating time (Hänniger et al., 2017; Pashley et al., 1992; Schöfl et al., 2009). As a result, releasing GM moths of a single strain may only effectively reduce that strain, and could conceivably even increase the population size of the alternative strain through competitive release, for example. In order to better understand these dynamics, studies on the ecology and behavior of fall armyworm strains are of the utmost importance. Diagnostic assays 
471 that can rapidly and reliably differentiate between strains can provide the necessary tools to

472 better understand these interstrain population dynamics.

473

\section{Conclusion}

475 The fall armyworm species, Spodoptera frugiperda, is comprised of two morphologically

476 identical strains that can only be distinguished using genetic markers. Here we identify four new

477 diagnostic markers with unique strain-specific alleles. Using these markers we developed and

478 validated Real-Time PCR assays to rapidly and reliably discriminate between strains in field-

479 collected samples. These diagnostic tools facilitate future studies on strain ecology and

480 population biology, allowing for better control of this economically important agricultural pest.

481

\section{Acknowledgements}

483 We would like to thank Texas A\&M Genomics and Bioinformatics (TxGEN) and the Texas

484

485

486

487

488

489

490

491

492

493

494

495

496
A\&M High Performance Research Computing (HPRC) for their services that made the sequencing and data analysis described in this study possible.

\section{References}

Asadi, R., Elaini, R., Lacroix, R., Ant, T., Collado, A., Finnegan, L., Siciliano, P., Mazih, A., Koukidou, M., 2020. Preventative releases of self-limiting Ceratitis capitata provide pest suppression and protect fruit quality in outdoor netted cages. International Journal of Pest Management 66, 182-193. doi:10.1080/09670874.2019.1601293

Banerjee, R., Hasler, J., Meagher, R., Nagoshi, R., Hietala, L., Huang, F., Narva, K., JuratFuentes, J.L., 2017. Mechanism and DNA-based detection of field-evolved resistance to transgenic Bt corn in fall armyworm (Spodoptera frugiperda). Scientific Reports 7. 
497

498

499

500

501

502

503

504

505

506

507

508

509

510

511

512

513

514

515

516

517

518

519

520

521

522

523

524

525

526

527

528

529

530

531

532

533

534

535

536

537

538

539

540

541

542

doi:10.1038/s41598-017-09866-y

Belay, D. K., Clark, P. L., Skoda, S. R., Isenhour, D. J., Molina-Ochoa, J., Gianni, C., Foster, J. E., 2012. Spatial genetic variation among Spodoptera frugiperda (Lepidoptera: Noctuidae) sampled from the United States, Puerto Rico, Panama, and Argentina. Annals of the Entomological Society of America 105, 359-367. https://doi.org/10.1603/AN11111

Bustin, S.A., Benes, V., Garson, J.A., Hellemans, J., Huggett, J., Kubista, M., Mueller, R., Nolan, T., Pfaffl, M.W., Shipley, G.L., Vandesompele, J., Wittwer, C.T., 2009. The MIQE guidelines: Minimum information for publication of quantitative real-time PCR experiments. Clinical Chemistry 55. doi:10.1373/clinchem.2008.112797

Carvalho, D.O., McKemey, A.R., Garziera, L., Lacroix, R., Donnelly, C.A., Alphey, L., Malavasi, A., Capurro, M.L., 2015. Suppression of a field population of Aedes aegypti in Brazil by sustained release of transgenic male mosquitoes. PLoS Neglected Tropical Diseases 9. doi:10.1371/journal.pntd.0003864

Chaisson, M.J., Tesler, G., 2012. Mapping single molecule sequencing reads using basic local alignment with successive refinement (BLASR): Application and theory. BMC

Bioinformatics 13, 238. doi:10.1186/1471-2105-13-238

Clark, P. L., Molina-Ochoa, J., Martinelli, S., Skoda, S. R., Isenhour, D. J., Lee, D. J., Krumm, J.T.Foster, J. E., 2007. Population variation of the fall armyworm, Spodoptera frugiperda, in the Western Hemisphere. Journal of Insect Science 7.

Danecek, P., Auton, A., Abecasis, G., Albers, C.A., Banks, E., DePristo, M.A., Handsaker, R.E., Lunter, G., Marth, G.T., Sherry, S.T., McVean, G., Durbin, R., 2011. The variant call format and VCFtools. Bioinformatics 27, 2156-2158. doi:10.1093/bioinformatics/btr330

Dumas, P., Legeai, F., Lemaitre, C., Scaon, E., Orsucci, M., Labadie, K., Gimenez, S., Clamens, A.L., Henri, H., Vavre, F., Aury, J.M., Fournier, P., Kergoat, G.J., D’Alençon, E., 2015. Spodoptera frugiperda (Lepidoptera: Noctuidae) host-plant variants: two host strains or two distinct species? Genetica 143, 305-316. doi:10.1007/s10709-015-9829-2

Goergen, G., Kumar, P.L., Sankung, S.B., Togola, A., Tamò, M., 2016. First report of outbreaks of the fall armyworm Spodoptera frugiperda (J E Smith) (Lepidoptera, Noctuidae), a new alien invasive pest in West and Central Africa. PLoS ONE 11. doi:10.1371/journal.pone.0165632

Gouin, A., Bretaudeau, A., Nam, K., Gimenez, S., Aury, J.M., Duvic, B., Hilliou, F., Durand, N., Montagné, N., Darboux, I., Kuwar, S., Chertemps, T., Siaussat, D., Bretschneider, A., Moné, Y., Ahn, S.J., Hänniger, S., Grenet, A.S.G., Neunemann, D., Maumus, F., Luyten, I., Labadie, K., Xu, W., Koutroumpa, F., Escoubas, J.M., Llopis, A., Maïbèche-Coisne, M., Salasc, F., Tomar, A., Anderson, A.R., Khan, S.A., Dumas, P., Orsucci, M., Guy, J., Belser, C., Alberti, A., Noel, B., Couloux, A., Mercier, J., Nidelet, S., Dubois, E., Liu, N.Y., Boulogne, I., Mirabeau, O., Le Goff, G., Gordon, K., Oakeshott, J., Consoli, F.L., Volkoff, A.N., Fescemyer, H.W., Marden, J.H., Luthe, D.S., Herrero, S., Heckel, D.G., Wincker, P., Kergoat, G.J., Amselem, J., Quesneville, H., Groot, A.T., Jacquin-Joly, E., Nègre, N., Lemaitre, C., Legeai, F., D’Alençon, E., Fournier, P., 2017. Two genomes of highly polyphagous lepidopteran pests (Spodoptera frugiperda, Noctuidae) with different hostplant ranges. Scientific Reports 7, 11816. doi:10.1038/s41598-017-10461-4

Groot, A.T., Marr, M., Heckel, D.G., Schöfl, G., 2010. The roles and interactions of reproductive isolation mechanisms in fall armyworm (Lepidoptera: Noctuidae) host strains. Ecol Entomol 35. doi:10.1111/j.1365-2311.2009.01138.x

Groot, A.T., Marr, M., Schöfl, G., Lorenz, S., Svatos, A., Heckel, D.G., 2008. Host strain

Peer) reviewing PDF | (2021:05:60854:1:0:NEW 18 Aug 2021) 
543

544

545

546

547

548

549

550

551

552

553

554

555

556

557

558

559

560

561

562

563

564

565

566

567

568

569

570

571

572

573

574

575

576

577

578

579

580

581

582

583

584

585

586

587

588

specific sex pheromone variation in Spodoptera frugiperda. Frontiers in Zoology 5. doi: 10.1186/1742-9994-5-20

Hänniger, S., Dumas, P., Schöfl, G., Gebauer-Jung, S., Vogel, H., Unbehend, M., Heckel, D.G., Groot, A.T., 2017. Genetic basis of allochronic differentiation in the fall armyworm. BMC Evolutionary Biology 17. doi:10.1186/s12862-017-0911-5

Hardke, J.T., Jackson, R.E., Leonard, B.R., Temple, J.H., 2015. Fall armyworm (Lepidoptera: Noctuidae) development, survivorship, and damage on cotton plants expressing insecticidal plant-incorporated protectants. Journal of Economic Entomology 108, 1086-1093. doi: $10.1093 /$ jee/tov092

Harvey-Samuel, T., Morrison, N.I., Walker, A.S., Marubbi, T., Yao, J., Collins, H.L., Gorman, K., Davies, T.G.E., Alphey, N., Warner, S., Shelton, A.M., Alphey, L., 2015. Pest control and resistance management through release of insects carrying a male-selecting transgene. BMC Biology 13. doi:10.1186/s12915-015-0161-1

Johnson, S.J., 1987. Migration and the life history strategy of the fall armyworm, Spodoptera frugiperda in the Western Hemisphere. Insect Science and it's applications 8, 543-549.

$\mathrm{JMP}^{\circledR}$, Version 14.0. SAS Institute Inc., Cary, NC, 1989-2021.

Kost, S., Heckel, D.G., Yoshido, A., Marec, F., Groot, A.T., 2016. A Z-linked sterility locus causes sexual abstinence in hybrid females and facilitates speciation in Spodoptera frugiperda. Evolution 70, 1418-1427. doi:10.1111/evo.12940

Levy, H.C., Garcia-Maruniak, A., Maruniak, J.E., 2002. Strain identification of Spodoptera frugiperda (Lepidoptera: Noctuidae) insects and cell lines: PCR-RFLP of cytochrome oxidase C subunit I gene. Florida Entomologist 85, 186-190. doi:10.1653/00154040(2002)085[0186:SIOSFL]2.0.CO;2

Lima, E.R., McNeil, J.N., 2009. Female sex pheromones in the host races and hybrids of the fall armyworm, Spodoptera frugiperda (Lepidoptera: Noctuidae). Chemoecology 19. doi:10.1007/s00049-009-0005-y

Liu, H., Lan, T., Fang, D., Gui, F., Wang, H., Guo, W., Cheng, X., Chang, Y., Lyu, L., Sahu, S.K., Cheng, L., Li, H., Fan, G., Liu, T., Hao, R., Lu, H., Zhu, S., Lu, Z., Huang, F., Dong, W., Dong, Y., Kang, L., Yang, H., Sheng, J., Liu, X., 2019. Chromosome level draft genomes of the fall armyworm, Spodoptera frugiperda (Lepidoptera : Noctuidae ), an alien invasive pest in China. BioRxiv 671560.

Livak, K.J., Flood, S.J.A., Marmaro, J., Giusti, W., Deetz, K., 1995. Oligonucleotides with fluorescent dyes at opposite ends provide a quenched probe system useful for detecting PCR product and nucleic acid hybridization. Genome Research 4, 357-362. doi: $10.1101 /$ gr.4.6.357

Luginbill, P., 1928. The fall army worm. USDA Technical Bulletin 34, 92.

Machado, V., Wunder, M., Baldissera, V.D., Oliveira, J. V, Fiuza, L.M., Nagoshi, R.N., 2008. Molecular characterization of host strains of Spodoptera frugiperda (Lepidoptera : Noctuidae) in Southern Brazil. Ann Entomol Soc Am 101. doi:10.1603/00138746(2008)101[619:MCOHSO]2.0.CO;2

Meagher, R.L., Nagoshi, R.N., 2004. Population dynamics and occurrence of Spodoptera frugiperda host strains in southern Florida. Ecological Entomology 29, 614-620. doi:10.1111/j.0307-6946.2004.00629.x

Montezano, D.G., Specht, A., Sosa-Gómez, D.R., Roque-Specht, V.F., Sousa-Silva, J.C., PaulaMoraes, S.V., Peterson, J.A., Hunt, T.E., 2018. Host plants of Spodoptera frugiperda (Lepidoptera: Noctuidae) in the Americas. African Entomology 26, 286-300. 
589

590

591

592

593

594

595

596

597

598

599

600

601

602

603

604

605

606

607

608

609

610

611

612

613

614

615

616

617

618

619

620

621

622

623

624

625

626

627

628

629

630

631

632

633

634

doi:10.4001/003.026.0286

Nagoshi, K.L., Allan, S.A., Meagher, R.L., Showler, A., 2020. Assessing the use of wing morphometrics to identify fall armyworm (Lepidoptera: Noctuidae) host strains in field collections. Journal of Economic Entomology 113. doi:10.1093/jee/toz344

Nagoshi, R. N. 2019. Evidence that a major subpopulation of fall armyworm found in the Western Hemisphere is rare or absent in Africa, which may limit the range of crops at risk of infestation. PloS one 14, e0208966. https://doi.org/10.1371/journal.pone.0208966

Nagoshi, R.N., 2012. Improvements in the identification of strains facilitate population studies of fall armyworm subgroups. Annals of the Entomological Society of America. doi:10.1603/an11138

Nagoshi, R.N., 2010. The fall armyworm triose phosphate isomerase (Tpi) gene as a marker of strain identity and interstrain mating. Annals of the Entomological Society of America 103, 283-292. doi:10.1603/an09046

Nagoshi, R.N., Fleischer, S., Meagher, R.L., Hay-Roe, M., Khan, A., Murúa, M.G., Silvie, P., Vergara, C., Westbrook, J., 2017. Fall armyworm migration across the lesser antilles and the potential for genetic exchanges between North and South American populations. PLoS ONE 12. doi:10.1371/journal.pone.0171743

Nagoshi, R.N., Meagher, R.L., 2008. Review of fall armyworm (Lepidoptera: Noctuidae) genetic complexity and migration. Florida Entomologist 91, 546-554. doi:doi: 10.1653/0015-404091.4.546

Nagoshi, R.N., Meagher, R.L., 2004. Seasonal Distribution of fall armyworm (Lepidoptera: Noctuidae) host strains in agricultural and turf grass habitats. Environmental Entomology 33, 881-889. doi:10.1603/0046-225x-33.4.881

Nagoshi, R. N., Meagher, R.L., Adamczyk, J.J., Braman, S.K., Brandenburg, R.L., Nuessly, G., 2006. New restriction fragment length polymorphisms in the cytochrome oxidase I gene facilitate host strain identification of fall armyworm (Lepidoptera: Noctuidae) populations in the southeastern United States. Journal of Economic Entomology 99, 671-677. doi:10.1093/jee/99.3.671

Nagoshi, R.N., Meagher, R.L., Flanders, K., Gore, J., Jackson, R., Lopez, J., Armstrong, J.S., Buntin, G.D., Sansone, C., Leonard, B.R., 2008. Using haplotypes to monitor the migration of fall armyworm (Lepidoptera: Noctuidae) corn-strain populations from Texas and Florida. Journal of Economic Entomology 101, 742-9.

Nagoshi, R.N., Meagher, R.L., Hay-Roe, M., 2012. Inferring the annual migration patterns of fall armyworm (Lepidoptera: Noctuidae) in the United States from mitochondrial haplotypes. Ecology and Evolution 2, 1458-1467. doi:10.1002/ece3.268

Otim, M.H., Tay, W.T., Walsh, T.K., Kanyesigye, D., Adumo, S., Abongosi, J., Ochen, S., Sserumaga, J., Alibu, S., Abalo, G., Asea, G., Agona, A., 2018. Detection of sister-species in invasive populations of the fall armyworm Spodoptera frugiperda (Lepidoptera: Noctuidae) from Uganda. PLoS ONE 13. doi:10.1371/journal.pone.0194571

Pashley, D.P., 1988. Current status of fall armyworm host strains. The Florida Entomologist 71, 227-234. doi:10.2307/3495425

Pashley, D.P., 1986. Host-associated genetic differentiation in fall armyworm (Lepidoptera: Noctuidae): A sibling species complex? Annals of the Entomological Society of America 79, 898-904. doi:10.1093/aesa/79.6.898

Pashley, D.P., Hammond, A.M., Hardy, T.N., 1992. Reproductive isolating mechanisms in fall armyworm host strains (Lepidoptera: Noctuidae). Annals of the Entomological Society of 
635

636

637

638

639

640

641

642

643

644

645

646

647

648

649

650

651

652

653

654

655

656

657

658

659

660

661

662

663

664

665

666

667

668

669

670

671

672

673

674

675

676

677

678

679

680

America 85, 400-405. doi:10.1093/aesa/85.4.400

Pashley, D.P., Martin, J.A., 1987. Reproductive incompatibility between host strains of the fall armyworm (Lepidoptera: Noctuidae). Annals of the Entomological Society of America 80, 731-733. doi:10.1093/aesa/80.6.731

Peterson, B.K., Weber, J.N., Kay, E.H., Fisher, H.S., Hoekstra, H.E., 2012. Double digest RADseq: An inexpensive method for de novo SNP discovery and genotyping in model and non-model species. PLoS ONE 7. doi:10.1371/journal.pone.0037135

Prasanna, B.M., Huesing, J.E., Eddy, R., Preschke, V.M., 2018. Fall armyworm in Africa: A guide for integrated pest management, First Edition. Mexico, CDMX: CIMMYT.

Prowell, D.P., McMichael, M., Silvain, J.F., 2004. Multilocus genetic analysis of host use, introgression, and speciation in host strains of fall armyworm (Lepidoptera : Noctuidae). Ann Entomol Soc Am 97. doi:10.1603/0013-8746(2004)097[1034:MGAOHU]2.0.CO;2

Puritz, J.B., Hollenbeck, C.M., Gold, J.R., 2014. dDocent : a RADseq, variant-calling pipeline designed for population genomics of non-model organisms. PeerJ 2, e431. doi: 10.7717 peerj.431

Rwomushana, I., Bateman, M., Beale, T., Beseh, P., Cameron, K., Chiluba, M., Clottey, V., Davis, T., Day, R., Early, R., Godwin, J., Gonzalez-Moreno, P., Kansiime, M., Kenis, M., Makale, F., Mugambi, I., Murphy, S., W., N., Phiri, N., Pratt, C., Tambo, J., 2018. Fall armyworm: impacts and implications for Africa. Evidence Note Update, October 2018, CABI.

Schlum, K.A., Lamour, K., de Bortoli, C.P., Banerjee, R., Meagher, R., Pereira, E., Murua, M.G., Sword, G.A., Tessnow, A.E., Viteri Dillon, D., Linares Ramirez, A.M., Akutse, K.S., Schmidt-Jeffris, R., Huang, F., Reisig, D., Emrich, S.J., Jurat-Fuentes, J.L., 2021. Whole genome comparisons reveal panmixia among fall armyworm (Spodoptera frugiperda) from diverse locations. BMC Genomics 22. doi:10.1186/s12864-021-07492-7

Schöfl, G., Dill, A., Heckel, D.G., Groot, A.T., 2011. Allochronic separation versus mate choice: Nonrandom patterns of mating between fall armyworm host strains. The American Naturalist 177, 470-485. doi:10.1086/658904

Schöfl, G., Heckel, D.G., Groot, A.T., 2009. Time-shifted reproductive behaviours among fall armyworm (Noctuidae: Spodoptera frugiperda) host strains: Evidence for differing modes of inheritance. Journal of Evolutionary Biology. doi:10.1111/j.1420-9101.2009.01759.x

Sharanabasappa, D., Kalleshwaraswamy, C.M., Poorani, J., Maruthi, M.S., Pavithra, H.B., Diraviam, J., 2019. Natural enemies of Spodoptera frugiperda (J. E. Smith) (Lepidoptera: Noctuidae), a recent invasive pest on maize in south India. The Florida Entomologist 102, 619-623. doi:10.1653/024.102.0335

Sparks, A.N., 1986. Fall armyworm (Lepidoptera: Noctuidae): potential for area-wide management. Florida Entomologist 69, 603-614. doi:10.2307/3495397

Sparks, A.N., 1979. A review of the biology of the fall armyworm. The Florida Entomologist 62, 82-87. doi:10.2307/3494083

Stokstad, E., 2020. Genetically engineered moths can knock down crop pests, but will they take off? Science. doi:10.1126/science.abb1078

Tay, W.T., Rane, R., Padovan, A., Walsh, T.K., Elfekih, S., Downes, S., Nam, K., D’Alençon, E., Zhang, J., Wu, Y., Nègre, N., Kunz, D., Kriticos, D.J., Czepak, C., Otim, M., Gordon, K.H.., 2020. Whole genome sequencing of global Spodoptera frugiperda populations: evidence for complex, multiple introductions across the Old World. bioRxiv. doi: $10.1101 / 2020.06 .12 .147660$

PeerJ reviewing PDF | (2021:05:60854:1:0:NEW 18 Aug 2021) 
681 Westbrook, J.K., Nagoshi, R.N., Meagher, R.L., Fleischer, S.J., Jairam, S., 2016. Modeling 682 seasonal migration of fall armyworm moths. International Journal of Biometeorology 60, 683 255-267. doi:10.1007/s00484-015-1022-x

684 Whitford, F., Quisenberry, S.S., Riley, T.J., Lee, J.W., 1988. Oviposition preference, mating 685 compatibility, and development of two fall armyworm strains. The Florida Entomologist 71, 686 234. doi: $10.2307 / 3495426$

687 Wiseman, B.R., 1985. IPM of fall armyworm and panicle caterpillars in sorghum, in:

688 Proceedings of the International Sorghum Entomology Workshop. pp. 219-232.

689 Zhang, L., Jin, M.H., Zhang, D.D., Jinag, Y.Y., Liu, J., Wu, K.M., Xiao, Y.T., 2019. Molecular 690 identification of invasive fall armyworm Spodoptera frugiperda in Yunnan Province. Plant 691 Protection 45, 19-24.

692 


\section{Figure 1}

Example RFLP analysis of known C-strain (C), R-strain (R), and interstrain hybrid $(\mathrm{H})$ fall armyworms.

Amplicons for COI or Tpi were digested with Mspl and Sacl as indicated in the figure. Since mtDNA is maternally inherited, the hybrid could not be distinguished from the R-strain using COI alone.

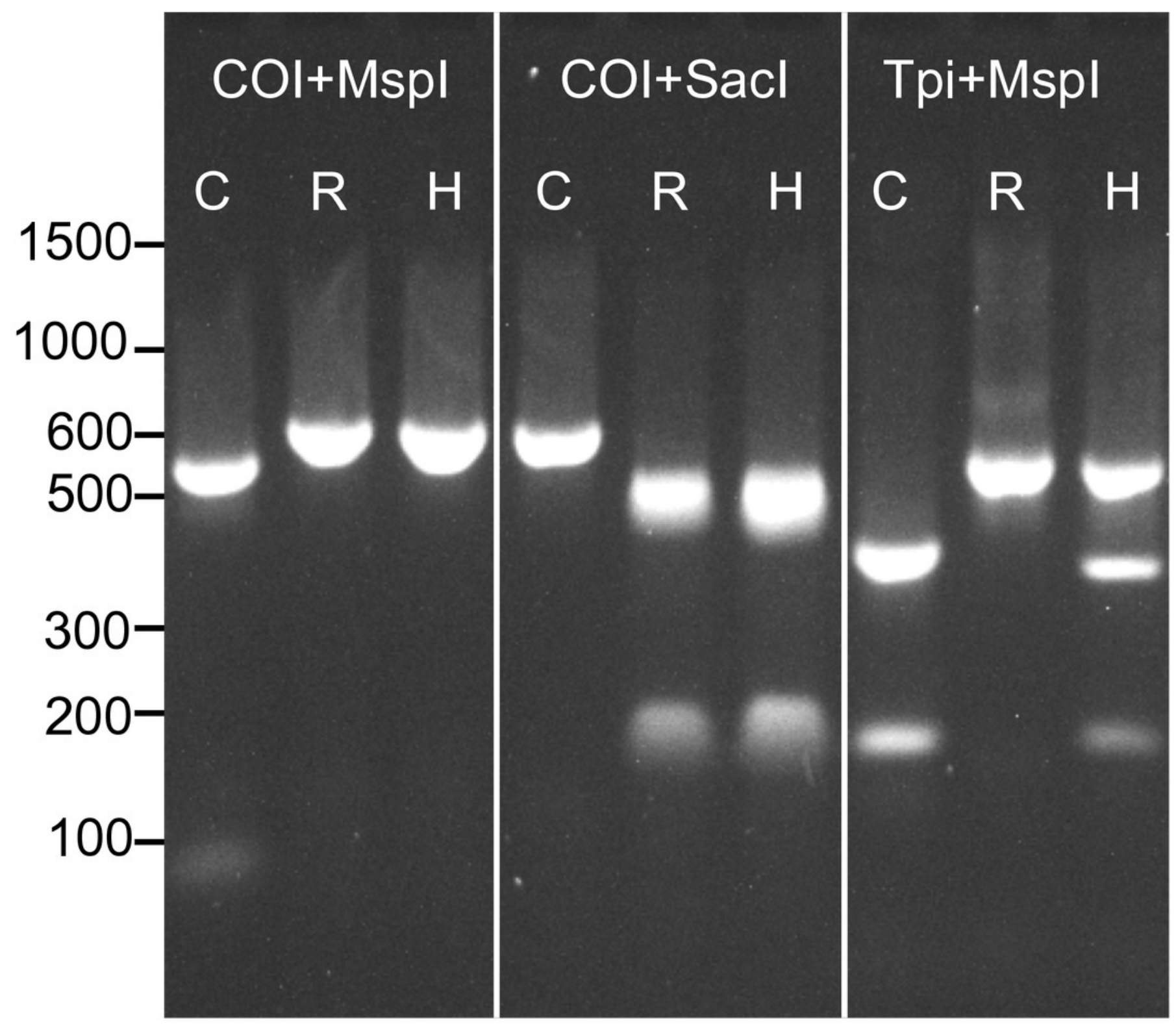




\section{Figure 2}

Percent of individuals for each diagnostic assay that were in agreement with the consensus strain.

Each bar is split into individuals that were determined to be R-strain, C-strain, or hybrids. No significant difference was detected in accuracy between the six assays $(p=0.07)$.

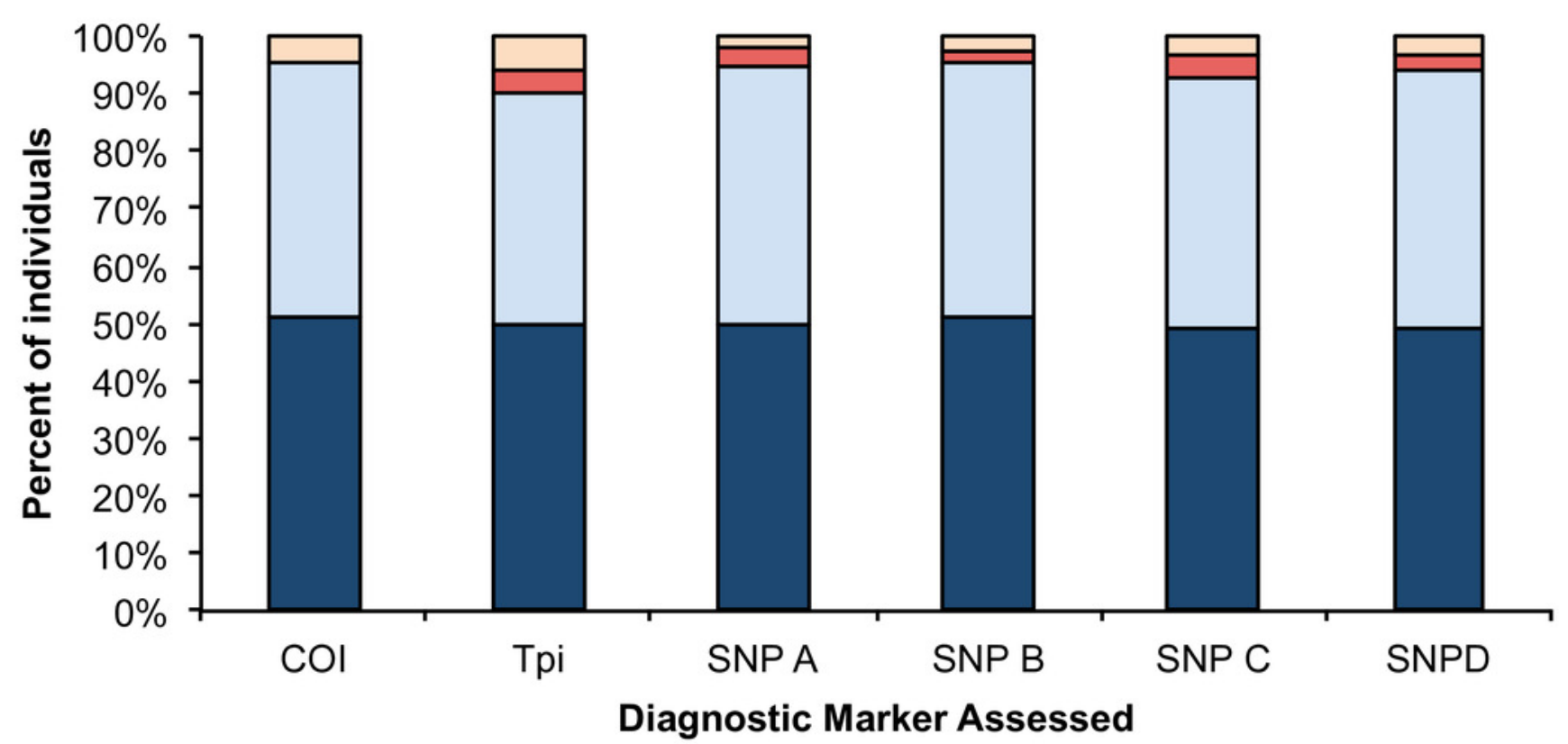

$\square$ Agreed with consensus: C-strain $\quad \square$ Agreed with consensus: R-strain

$\square$ Agreed with consensus: Hybrid पDisagreed with consensus 
Figure 3

Standard curve relating the DNA concentration within a reaction to the expression of both the VIC (dashed) and FAM fluorophore (solid line).

The standard curve for each TaqMan real-time PCR assays is demonstrated as a separate panel: (a) SNP A assay, (b) SNP B assay, (c) SNP C assay, and (d) SNP D assay. Corresponding slopes and $R^{2}$ values are reported.

(a)

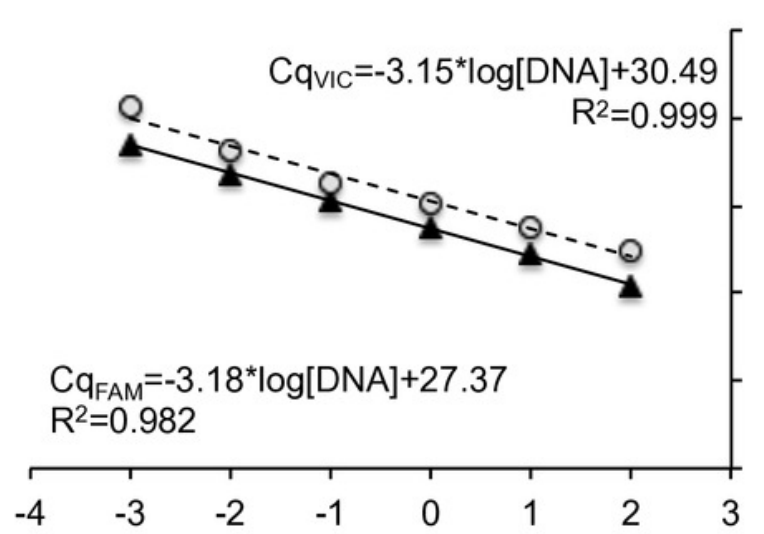

(c)

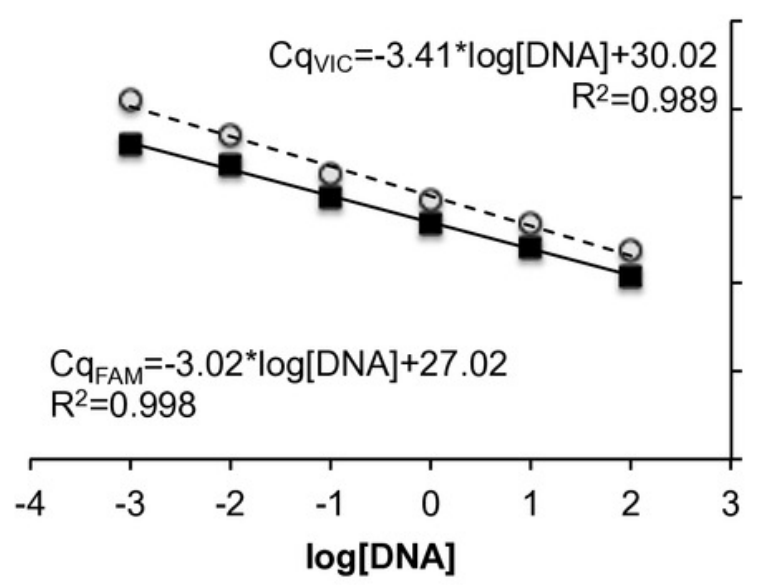

$\triangle$ FAM $O$ VIC - Linear (FAM) ---Linear (VIC) (b)

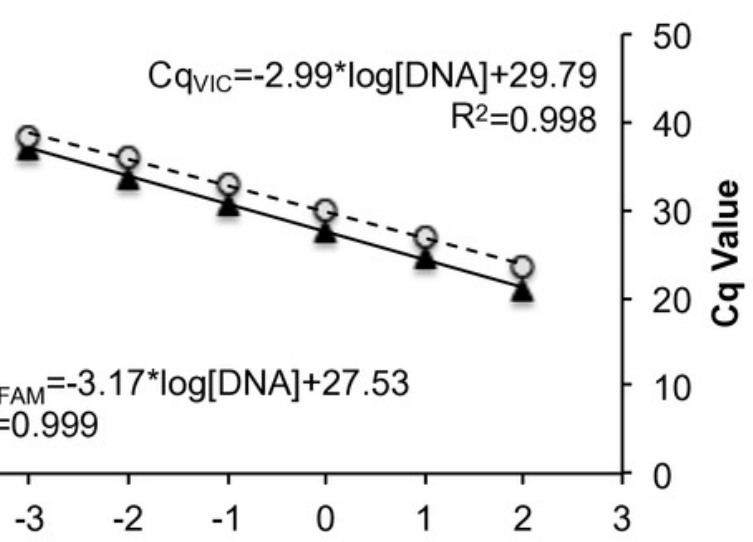

(d)

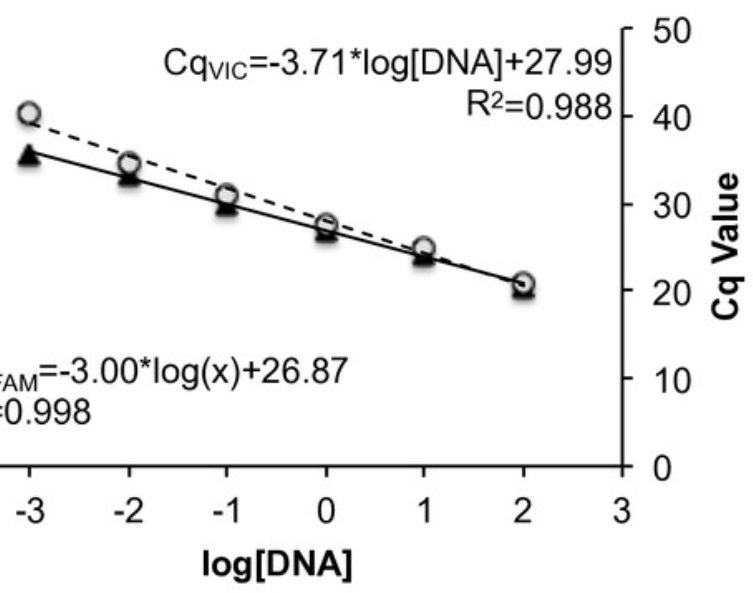




\section{Table $\mathbf{1}$ (on next page)}

Sampling location and collection date for all moths sequenced for the initial assay development.

Both the number of individuals per predetermined strain mitochondrial haplotype (R- or C-) and number of total individuals from each collection (R- + C-) is provided. 
1

\begin{tabular}{|c|c|c|c|c|c|}
\hline & & & & eque & ced \\
\hline Location & Date & GPS Coordinates & R- & C- & Total \\
\hline & 3-15 March 2017 & $\begin{array}{r}26.1556,-97.9618 \& \\
26.2099,-97.5432\end{array}$ & 22 & 16 & 6 \\
\hline Lower Rin Grande & 16 November 2017 & $26.1556,-97.9618$ & 12 & 0 & 12 \\
\hline Valley, TX & 10-11 May 2018 & $\begin{array}{r}26.0924,-97.8814 \& \\
26.0869,-98.2601\end{array}$ & 22 & 15 & 7 \\
\hline & 12-13 July 2018 & $26.1556,-97.9618$ & 23 & 22 & 1 \\
\hline & 11-12 December 2018 & $26.1556,-97.9618$ & 18 & 1 & 17 \\
\hline & 18-20 April 2017 & $27.7827,-97.5621$ & 20 & 1 & 20 \\
\hline & 28-30 September 2017 & $27.7827,-97.5621$ & 19 & 3 & 16 \\
\hline Corpus Christi, TX & 12-13 Мay 2018 & $27.7827,-97.5621$ & 18 & 10 & 8 \\
\hline & 10-11 July 2018 & $27.7827,-97.5621$ & 14 & 13 & 1 \\
\hline & 7-8 October 2018 & $27.7827,-97.5621$ & 13 & 0 & 13 \\
\hline & 25-26 May 2017 & $30.6206,-96.3617$ & 22 & 10 & 13 \\
\hline & 6-7 July 2017 & $30.6206,-96.3617$ & 16 & 16 & 0 \\
\hline Collous Station TY & 23-27 October 2017 & $30.6206,-96.3617$ & 13 & 0 & 12 \\
\hline Conege Station, IA & 16-18 May 2018 & $30.6206,-96.3617$ & 18 & 7 & 11 \\
\hline & 28-29 June 2018 & $30.6206,-96.3617$ & 15 & 10 & 5 \\
\hline & 19-24 October 2018 & $30.6206,-96.3617$ & 12 & 0 & 12 \\
\hline & 24-31 May 2017 & $33.6912,-101.8259$ & 15 & 15 & 0 \\
\hline & 21-27 June 2017 & $33.6912,-101.8259$ & 23 & 16 & 7 \\
\hline I ubhock TX & 21 September 2017 & $33.6912,-101.8259$ & 22 & 13 & 9 \\
\hline LUDDOck, $1 \mathrm{X}$ & 2 May 2018 & $33.6912,-101.8259$ & 12 & 12 & 0 \\
\hline & 12 June 2018 & $33.6912,-101.8259$ & 12 & 11 & 1 \\
\hline & 13 September 2018 & $33.6912,-101.8259$ & 18 & 13 & 5 \\
\hline Rosemount MN & 12-14 September 2017 & $44.7069,-93.1068$ & 28 & 18 & 8 \\
\hline Kosemount, MNN & 21 August 2018 & $44.7069,-93.1068$ & 20 & 20 & 0 \\
\hline
\end{tabular}

2 


\section{Table 2 (on next page)}

Design information for all diagnostic assays included in this study.

The primer and probe sequences, chromosomal positions (Liu et al. 2019), alleles associated with the C- and R-strain, and the expected length of the PCR product are included for each TaqMan real-time PCR assay. Additionally, the primer sequences and expected PCR product length are listed for both the $\mathrm{COI}$ and Tpi diagnostic assays. 


\begin{tabular}{|c|c|c|c|c|c|c|}
\hline SNP & Chrom & Position (bp) & $\begin{array}{l}\text { PCR } \\
\text { Product }\end{array}$ & $\begin{array}{c}\mathbf{C} / \mathbf{R} \\
\text { allele } \\
\end{array}$ & Description & Sequence \\
\hline \multirow{4}{*}{ SNP A } & \multirow{4}{*}{$1 / Z$} & \multirow{4}{*}{$14,104,488$} & \multirow{4}{*}{$62 \mathrm{bp}$} & \multirow{4}{*}{$\mathrm{A} / \mathrm{G}$} & Forward Primer & 5'-GCAAGTGCAATTTTCCCATCTGATG \\
\hline & & & & & Reverse Primer & 5'-CAAGCCGTTCGCGGTTAG \\
\hline & & & & & FAM Probe Sequence & 5'-FAM-AGACCAAAAGGACTCAT-MGB-NFQ \\
\hline & & & & & VIC Probe Sequence & 5'-VIC-CTAGACCAAAAAGACTCAT-MGB-NFQ \\
\hline \multirow{4}{*}{ SNP B } & \multirow{5}{*}{$1 / Z$} & \multirow{5}{*}{$4,933,322$} & \multirow{4}{*}{$113 \mathrm{bp}$} & \multirow{4}{*}{$\mathrm{G} / \mathrm{C}$} & Forward Primer & 5'-GGGAACTCATATACTAAAATCGGAAAAACCT \\
\hline & & & & & Reverse Primer & 5'-ACACTCGCATTATTTGTGTGCAATT \\
\hline & & & & & FAM Probe Sequence & 5'-FAM-CCGCAGTAGCGTATGT-MGB-NFQ \\
\hline & & & & & VIC Probe Sequence & 5'-VIC-TCCGCAGTACCGTATGT-MGB-NFQ \\
\hline \multirow{4}{*}{ SNP C } & & & \multirow{4}{*}{$57 \mathrm{bp}$} & \multirow{4}{*}{$\mathrm{C} / \mathrm{T}$} & Forward Primer & 5'-TGACAGCATTGATGTGCTGGAT \\
\hline & \multirow{3}{*}{$1 / Z$} & \multirow{3}{*}{$4,683,787$} & & & Reverse Primer & 5'-CGCCGGAGCGTTACAGA \\
\hline & & & & & FAM Probe Sequence & 5'-FAM-CGCTACCAAAGCCAG-MGB-NFQ \\
\hline & & & & & VIC Probe Sequence & 5'-VIC-CGCTACCAGAGCCAG-MGB-NFQ \\
\hline \multirow{4}{*}{ SNP D } & \multirow{4}{*}{16} & \multirow{4}{*}{$14,134,047$} & \multirow{4}{*}{$70 \mathrm{bp}$} & \multirow{4}{*}{$\mathrm{C} / \mathrm{G}$} & Forward Primer & 5'-TGAGTGCCAACAGCTATCTTCTG \\
\hline & & & & & Reverse Primer & 5'-GCAGTCCATTACAGCTGGTGAA \\
\hline & & & & & FAM Probe Sequence & 5'-FAM-AGCTCATGTCCTACTCC-MGB-NFQ \\
\hline & & & & & VIC Probe Sequence & 5'-VIC-AGCTCATGTCGTACTCC-MGB-NFQ \\
\hline \multirow{3}{*}{$\mathrm{COI}^{1}$} & \multirow{3}{*}{ mtDNA } & \multirow{4}{*}{-} & \multirow{3}{*}{568 bp } & \multirow{3}{*}{-} & $J M-76$ Forward Primer & 5'-GAGCTGAATTAGG (G/A)ACTCCAGG \\
\hline & & & & & $J M-77$ Reverse Primer & 5'-ATCACCTCC(A/T)CCTGCAGGATC \\
\hline & & & & & Tpi-632 Forward Primer & 5'-GGTTGCCCATGCTCTTGAGTCCGGACTGAAGG \\
\hline$T p i^{2}$ & $1 / Z$ & & $\sim 600 \mathrm{bp}$ & - & Tpi-1195 Reverse Primer & 5'-AGTCACTGACCCACCATACTG \\
\hline
\end{tabular}

21 Primers were originally developed by Levy et al. (2002) and made available by Nagoshi et al. (2006).

$3 \quad 2$ Primers were originally developed and published by Nagoshi et al. (2012). 


\section{Table 3(on next page)}

Collection information for all samples used to validate the four TaqMan real-time PCR assays. 
1

\begin{tabular}{cllcc}
\hline & Location & Date & \# Samples & Strain if known \\
\hline & Weslaco, TX & 11 December 2018 & 3 & R \\
& Corpus Christi, TX & 13 May 2018 & 1 & Hybrid \\
Validation 1: & Corpus Christi, TX & 10 July 2018 & 2 & C \\
Known & Corpus Christi, TX & 19 October 2018 & 2 & R \\
samples, & College Station, TX & 24 October 2017 & 1 & Hybrid \\
sequences & College Station, TX & 18 May 2018 & 3 & R \\
used in assay & College Station, TX & 28 June 2018 & 2 & C \\
creation & Lubbock, TX & 2 May 2018 & 2 & C \\
& Lubbock, TX & 12 June 2018 & 1 & Hybrid \\
& Rosemount, MN & 12 September 2017 & 1 & Hybrid \\
& Rosemount, MN & 21 August 2018 & 2 & C \\
\hline Validation 2: & College Station, TX & 20 October 2018 & 12 & $?$ \\
Central & College Station, TX & 13 June 2020 & 24 & $?$ \\
Population & Lubbock, TX & 2 May 2018 & 6 & $?$ \\
Unknowns & Rosemount, MN & 21 August 2018 & 6 & $?$ \\
\hline \multirow{2}{*}{ Validation 3: } & Collier, FL & 15-24 February 2012 & 9 & $?$ \\
Eastern & Tifton, GA & 7 August 2014 & 10 & $?$ \\
Population & Jarretsville, MD & 3-30 August 2017 & 9 & $?$ \\
Unknowns & Charleston, SC & 30 June 2017 & 10 & $?$ \\
& Roper, NC & 16 November 2017 & 6 & $?$ \\
\hline
\end{tabular}




\section{Table 4 (on next page)}

Mean $\Delta$ Cq within each strain for reactions in which both fluorophores were detected.

This indicates the number of cycles after the initial strain specific fluorophore was detected until the secondary flourophore was detected above threshold. The FAM flourophore is associated with the R-strain whereas the VIC flourophore is associated with the C-strain. 
1

\begin{tabular}{lll}
\hline & $\boldsymbol{\Delta C q} \pm \mathbf{S D}$ within R-strain & $\mathbf{\Delta} \mathbf{C q} \pm \mathbf{S D}$ within C-strain ${ }^{\mathbf{2}}$ \\
\hline SNP A & Only FAM detected & $7.05 \pm 0.89$ \\
SNP B & $16.26 \pm 1.26$ & $17.12 \pm 1.38$ \\
SNP C & $10.32 \pm 0.97$ & Only VIC detected \\
SNP D & $3.67 \pm 0.29$ & $5.77 \pm 0.45$ \\
\hline
\end{tabular}

2

${ }^{1}$ In R-strain individuals the FAM fluorophore was detected first, so $\Delta$ Cq was calculated as $\mathrm{Cq}_{\text {VIC }}-\mathrm{Cq}_{\mathrm{FAm}}$.

${ }^{2}$ In C-strain individuals the VIC fluorophore was detected first, so $\Delta \mathrm{Cq}$ was calculated as $\mathrm{Cq}_{\mathrm{FAM}}-\mathrm{Cq}_{\mathrm{VIC}}$.

6

7 